\title{
Electrophysiological and behavioral indicants of selective attention to multifeature gratings
}

\author{
FRED H. PREVIC and M. RUSSELL HARTER \\ The University of North Carolina at Greensboro, Greensboro, North Carolina
}

\begin{abstract}
The mechanisms underlying selective attention to gratings consisting of a particular conjunction of spatial frequency and orientation were investigated by means of both visual evoked potential (VEP) and behavioral measures. The effects of selective attention upon the VEP indicated two general types of selection processes: one which is specific to the features contained in the relevant gratings and is most pronounced approximately $225 \mathrm{msec}$ poststimulation, and another which is specific to the conjunction of features defining the relevant grating and is most pronounced 250-375 msec following the presentation of the stimulus. The behavioral responses primarily reflected this latter, or grating-specific, attentional process. The results are discussed in terms of the role of sensory feature channels in mediating selective attention to visual stimuli and are related to various information processing models of visual pattern selection.
\end{abstract}

The neural mechanisms underlying intramodal selective attention in humans have been investigated using the visual evoked potential (VEP) in a variety of different contexts (see Eason, Harter, \& White, 1969; Harter \& Guido, 1980; Harter \& Previc, 1978; Harter \& Salmon, 1972; Van Voorhis \& Hillyard, 1977). Although the visual stimuli in these and other studies have varied along several types of dimensions, including spatial location, check size, orientation, and color, in no case have the attended and nonattended stimuli varied orthogonally along more than one feature dimension. Such a manipulation is necessary to assess the extent to which attention influences the processing of features as compared with the conjunction of features. In the present study, the effect of selective attention upon VEPs to gratings varying along two feature dimensions-spatial frequency and orientation-was examined.

The nature of spatial frequency and orientation sensitivity in humans has been widely investigated by means of both psychophysical and electrophysiological techniques (see Braddick, Campbell, \& Atkinson, 1978, for a review). The specificity of such sensitivity has been characterized in terms of "channels" associated with a particular bandwidth for a particular feature. Spatial frequency and orientation channels

This experiment was supported by a Research Council grant from the University of North Carolina at Greensboro. Portions of these data were presented at the Carmel Conference on ERP Measures of Information Processing: Cognitive Functioning, Carmel, California, 1979, and were published in the proceedings of the Conference on Human Evoked Potentials, Konstanz, West Germany, 1977. Special thanks are offered to Leo Towle for his many contributions to this study. F. H. Previc's present address is: Technology Incorporated, 300 Breesport, San Antonio, Texas 78216. have generally been viewed as at least partially interdependent.

By means of an interocular suppression paradigm, the VEP has been employed in order to investigate the nature of, and interaction between, spatial frequency and orientation channels in the human visual system (Harter, Conder, \& Towle, 1980; Harter \& Musso, 1976; Towle, Harter, \& Previc, 1980). The results of the Towle et al. (1980) study revealed that the onset of orientation-specific suppression (approximately $100 \mathrm{msec}$ poststimulation) preceded the onset of spatial frequency-specific suppression by over $100 \mathrm{msec}$. The results of this study also indicated that whereas the initial orientation and spatial frequency-specific suppression effects were largely independent of one another, later suppression effects were dependent upon an interaction between the two channels, that is, were limited to the condition in which the spatial frequency and orientation of the suppressing and flashed gratings were in common.

Harter and Previc (1978) tested the hypothesis that feature-specific channels, such as those described above, may be influenced by selective attention to particular features. Their results supported this hypothesis in that the influence of selective attention to spatial frequency closely resembled the effects of spatial frequency-specific suppression upon the VEP. Harter and Guido (1980) further demonstrated that the scalp topography of orientation-specific VEP attention effects was similar to that of the VEP effects associated with the processing of the pattern per se.

In the present study, it was similarly hypothesized that the "endogenous" effects of selectively attending gratings of a particular spatial frequency and orientation would closely resemble the "exogenous" 
interocular suppression effects obtained by Towle et al. (1980). Specifically, it was predicted that (1) selective attention to a grating of a particular orientation and spatial frequency would initially result in feature-specific changes in VEPs to both the relevant grating as well as irrelevant gratings whose orientation or spatial frequency was identical to that of the relevant grating, (2) the onset and duration of these feature-specific effects would be comparable to those obtained using the sensory interocular suppression paradigm, and (3) later VEP selection effects would be specific to the conjunction of features in the relevant grating, that is, to the relevant grating per se.

\section{METHOD}

\section{Subjects}

Seven graduate students and one faculty member of the University of North Carolina at Greensboro participated in the study. Half of the subjects had served previously in a similar type of study, All possessed a monocular (right eye) visual acuity of $20 / 40$ or better.

\section{Visual Presentation}

The high-contrast (.9) square-wave stimulus transparencies employed were identical to those used by Towle et al. (1980). The gratings comprised either 9- or 36-min bars (i.e., fundamental spatial frequencies of 3.3 and .83 cycles/deg, respectively) and were oriented either horizontally or vertically. The four gratings will be referred to hereafter as $9 \mathrm{~V}, 9 \mathrm{H}, 36 \mathrm{~V}$, and $36 \mathrm{H}$. A transparency was back-illuminated once every $780 \mathrm{msec}$ with a 10 -msec flash generated by a Grass PS-2 photostimulator. The four gratings were flashed successively in a random sequence.

The flashed gratings, subtending 4 deg of visual arc, were presented at a distance of $53 \mathrm{~cm}$ through an artificial pupil to the macular area of the right eye. Each flash was $2.8 \mathrm{log}$ units in intensity above a 4-mL diffuse background field.

\section{Attention Task}

In performing the selective-attention task, subjects were required to respond selectively to a grating of a particular spatial frequency and orientation, and to ignore the other three gratings. The task was made demanding by the imposition of a stringent reaction-time (RT) response criterion in which the release of a microswitch key was required within $375 \mathrm{msec}$ following the presentation of the relevant stimulus. Failure to do so resulted in the presentation of a feedback click. A signal-detection categorization scheme was employed in evaluating subjects' performances. Responses to relevant stimuli occurring within the 375 -msec interval were "hits"; responses to irrelevant stimuli were "false alarms"; delayed or absent responses to relevant stimuli were "misses"; and with held responses to irrelevant stimuli were "correct rejections." If the percentage of "hits" or "correct rejections" failed to exceed $75 \%$, the subjects were required to repeat the task.

\section{Visual Evoked Potentials}

Cortical responses to the patterned flashes were recorded by means of Grass GS gold-plated cup electrodes. Recording was monopolar, with the source electrode placed $2.5 \mathrm{~cm}$ above the inion, and the reference electrode attached to the right ear lobe. A ground electrode was attached to the left ear lobe. Resistance was maintained below $10 \mathrm{ke}$ by the use of Redux electrode jelly. Responses were amplified by a Grass 7P5A preamplifier and a 7DA amplifier, with one-half-amplitude low- and high-frequency filters set at 1 and $35 \mathrm{~Hz}$, respectively. Cortical activity was monitored on a Dumont 708A oscilloscope.
A Fabri-Tek 1062 computer was used for signal averaging. Averaged VEPs $(\mathrm{N}=64)$ to the $9 \mathrm{~V}$ and $36 \mathrm{H}$ gratings were obtained in each of the four attention conditions $(9 \mathrm{~V}, 9 \mathrm{H}, 36 \mathrm{~V}$, and $36 \mathrm{H})$. Averaged evoked potentials for each condition were permanently recorded on graph paper using a Hewlett-Packard 7035B X-Y recorder. The baseline for each potential was defined as the average voltage level during the first $50 \mathrm{msec}$ following the onset of the stimulus. All amplitude measurements were derived in reference to this baseline.

\section{Overall Design and Procedure}

The present experiment comprised four selective attention conditions, with one of the four gratings $(9 \mathrm{~V}, 9 \mathrm{H}, 36 \mathrm{~V}$, or $36 \mathrm{H})$ deemed relevant in each of the conditions. In these conditions, therefore, the grating to which VEPs were recorded either (1) had both spatial frequency and orientation in common with the relevant grating, that is, was itself relevant, (2) had spatial frequency or orientation in common with the relevant grating, or (3) had neither feature in common with the relevant grating. The $9 \mathrm{~V}$ grating, for instance, was relevant in the $9 \mathrm{~V}$ condition, had spatial frequency and orientation in common in the $9 \mathrm{H}$ and $36 \mathrm{~V}$ conditions, respectively, and had neither feature in common in the $36 \mathrm{H}$ condition.

Obtaining VEPs to the $9 \mathrm{~V}$ and $36 \mathrm{H}$ gratings during the four attention conditions comprised a single replication requiring approximately $11 / 2 \mathrm{~h}$. Four replications were run, each on a different day. Both the order of recording and the order of the four attention conditions were counterbalanced across subjects and replications by means of a Latin-square design.

At the start of each session (replication), the subject was led into an electronically shielded, partially soundproofed cubicle, and seated in a comfortable chair. The experimenter then explained the nature of the task, and instructed the subject to minimize movement, fixate on the center of the display, and avoid blinking during the presentation of stimuli. The subjects were presented with a switch by means of which they could stop or start the presentation of stimuli, and allowed to practice the task which they were later to perform. White masking noise was then introduced into the experimental chamber, and the session was begun.

\section{RESULTS}

In assessing statistically the results of this study, a four-factor repeated-measures design was employed. As shown in Figure 1, the four attention conditions described in the preceding section were transformed into two of these factors, based upon whether the

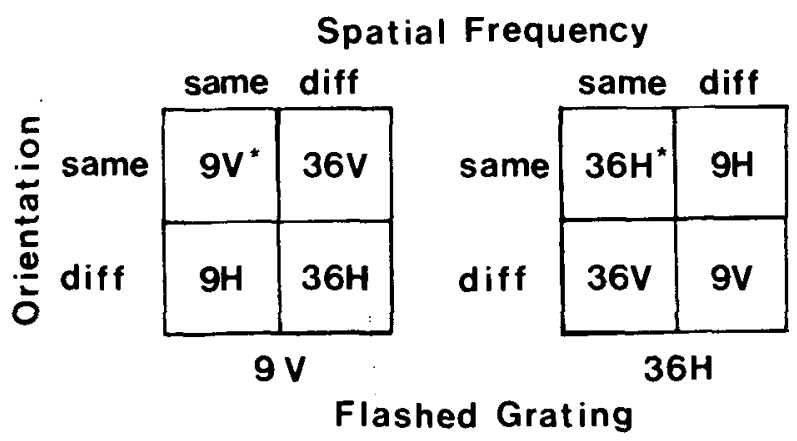

Figure 1. Slmilarity of features in the relevant (in boxes) and nashed gratings. Asterisk denotes the condition in which the nashed grating was itself relevant; in all others, the flashed grating was irrelevant. 
spatial frequency and/or orientation of the flashed grating $(9 \mathrm{~V}$ or $36 \mathrm{H})$ were identical or not to those of the relevant grating. In this arrangement, then, the main effects reflected feature-specific attention effects. The grating-specific attention effect, the additional effect of attending to the conjunction of features contained in the relevant grating, was reflected in the interaction between the spatial frequency and orientation factors.

The two other factors were flashed grating (9V vs. $36 \mathrm{H}$ ) and replication (1-4). The results were analyzed statistically by means of a repeated-measures analysis of variance (Keppel, 1973).

\section{Behavioral Findings}

The percentage of RT responses in the four attention conditions, averaged across the $9 \mathrm{~V}$ and $36 \mathrm{H}$ gratings, is shown in Figure 2. As evidenced, the percentage of RT responses to the two gratings was greatest when they were relevant (i.e., "hits"). This grating-specific effect was, of course, a consequence of the RT response requirements. On the other hand, a considerable number of responses were made to the $9 \mathrm{~V}$ and $36 \mathrm{H}$ gratings when they were irrelevant (i.e., "false alarms"), but had a single feature in common with the relevant grating. The feature-specific effect was most pronounced in the case of spatial frequency. Both the spatial frequency $[F(1,7)=2,268.46$, $\mathrm{p}<.001]$ and orientation $[\mathrm{F}(1,7)=408.6, \mathrm{p}<.001]$ feature-specific effects proved highly significant, as

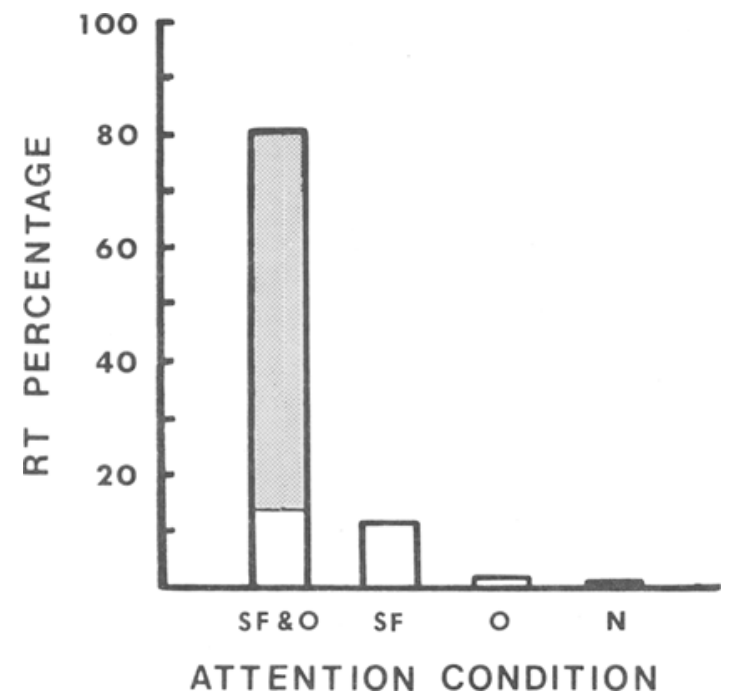

Figure 2. Percentage of RT responses as a function of the features common to the flashed and relevant grating: spatial frequency and orientation (SF $\&$ ), only spatial frequency (SF), ouly orientation (O), and neither spatial frequency nor orlentation (N). The shaded aren indicates that portion of the "SF $O$ " effect which cannot be accounted for by the summation of the "SF" plus " $O$ " feature effects. Reaction-time percentages are averaged across the two fashed gratings, eight subjects, and four replications.

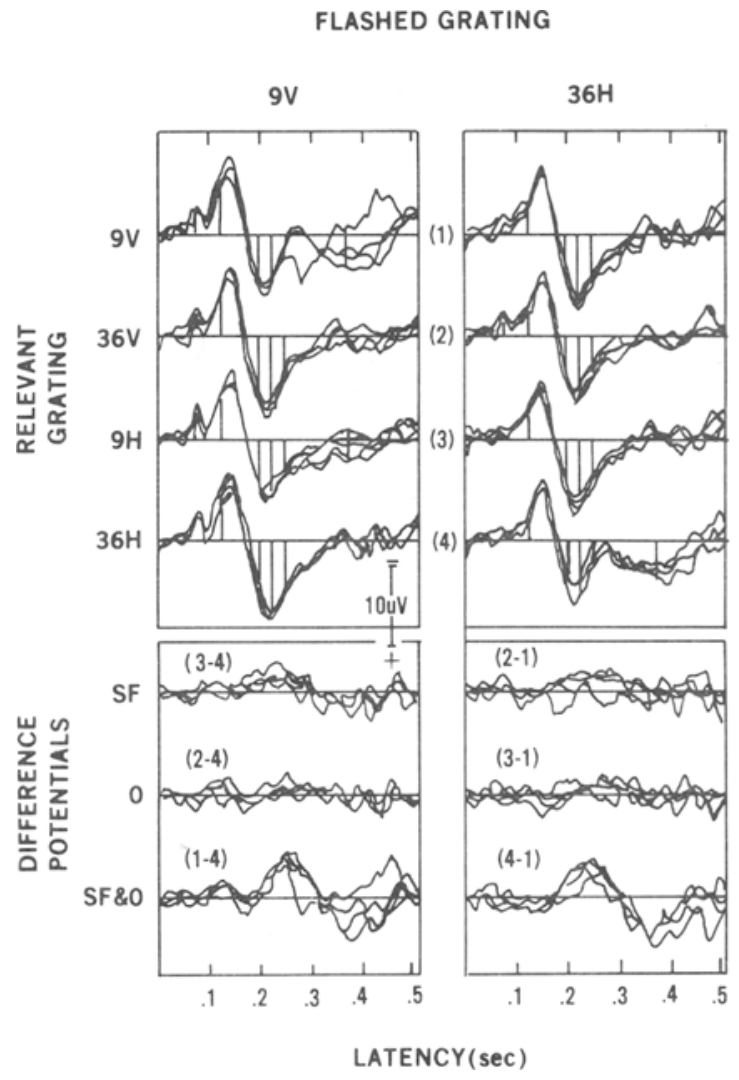

Figure 3. Top: Visual evoked potentials for a representative subject to the $9 \mathrm{~V}$ and $36 \mathrm{H}$ gratings under the four attention conditions. Lines indicate latencles at which amplitude measurements were made. Bottom: Difference potentials, based upon the potentials shown above, revealing the increase in amplitude from the "neither" feature in common condition to only spatial frequency (SF), only orientation ( $O$ ), and the conjunction of both features (SF \& O) in common with the relevant grating.

did the spatial frequency $\times$ orientation interaction $[F(1,7)=301.08, p<.001]$, reflecting the influence of grating-specific attention.

Two other interaction effects which were not of theoretical relevance also proved significant for the behavioral data. These were the flashed grating $x$ orientation $[F(1,7)=11.45, p<.05]$ and the flashed grating $\times$ spatial frequency $\times$ orientation $[F(1,7)=$ $14.81, p<.01]$ interactions.

\section{VEP Findings}

The amplitude of the VEP was measured at the following latencies: $75,125,175,200,225,250$, and $375 \mathrm{msec}$, poststimulation. A set of VEPs and associated difference potentials is shown for a representative subject (Figure 3) and for the quantified data averaged across all eight subjects (Figure 4). In deriving the difference potentials, VEPs to the $9 \mathrm{~V}$ and $36 \mathrm{H}$ flashed gratings when neither of their features was common to those of the relevant grating were subtracted from VEPs to those same gratings 

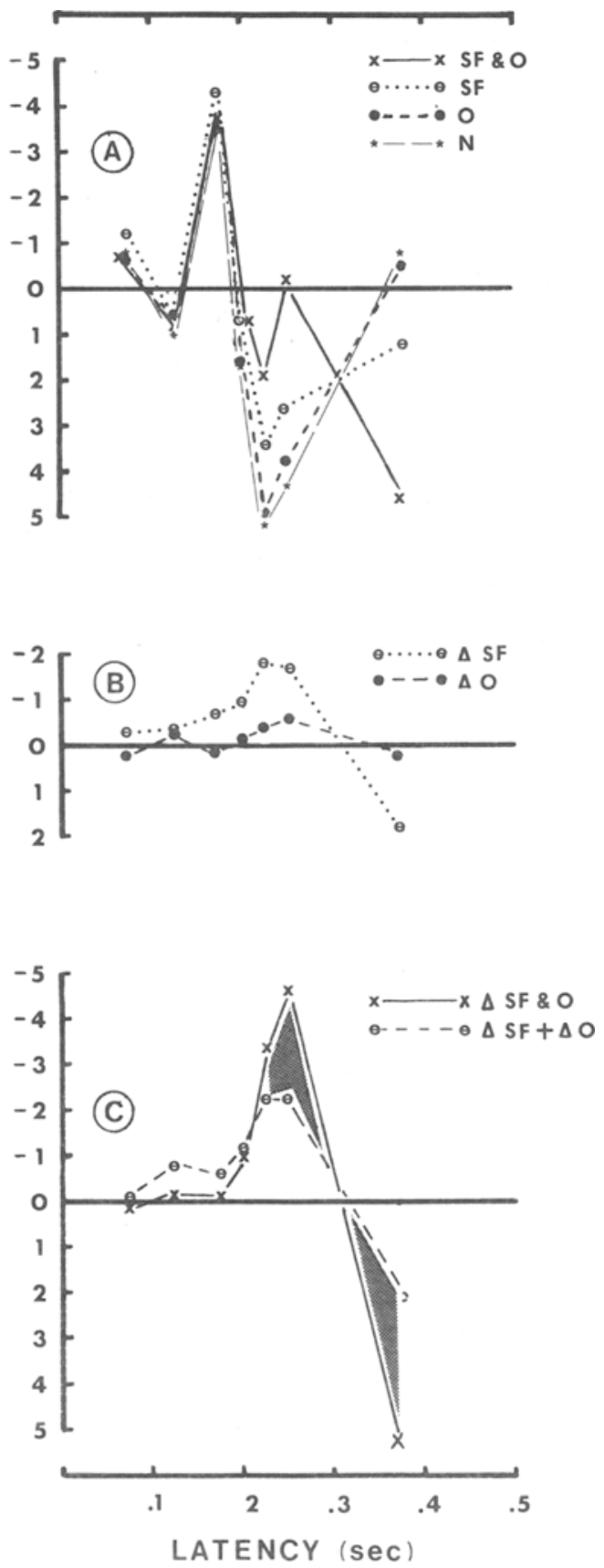

Figure 4. (A) Visual evoked potentials based upon the quantified data, and averaged across the two fashed gratings, eight subjects, and four replications. The four VEPs correspond to the four attention conditions which varled in terms of the features common to the fiashed and relevant grating. (B) Difference potentials based upon the VEPs shown in (A) revealing the increase in amplitude due to having only spatial frequency ( $S F-N=\Delta S F$ ) or only orientation $(O-N=\Delta O)$ common to both the relevant and flashed gratings. (C) The effect of having the conjunction of spatial frequency and orientation (SF $\& 0-N=\Delta$ SF $\& 0$ ) common to the fiashed and relevant gratings $(x-X)$, and the sum of the featureattention effects shown In (B) $(\Theta---\theta)$. Grating-specific attention is reflected in the difference between these two curves (shaded area). when a single feature was in common (spatial frequency or orientation), and when $9 \mathrm{~V}$ and $36 \mathrm{H}$ were themselves relevant (spatial frequency and orientation common).

Figure 5 contains bar graphs further depicting the feature-specific and grating-specific attention effects on VEP amplitude at those latencies at which the effects were most pronounced (225 and $375 \mathrm{msec}$, respectively).

The data in Figures 4 and 5 have been averaged across the $9 \mathrm{~V}$ and $36 \mathrm{H}$ gratings, since they reflected similar trends.

VEP feature-specific attention effects. Featurespecific attention effects are displayed as the spatial frequency and orientation difference potentials in Figure 4b. The spatial-frequency attention effect was first evident as an increase in negativity starting at approximately $175 \mathrm{msec}$. This negative voltage shift peaked at $225 \mathrm{msec}$ (see Figure 5), and was followed shortly thereafter by a positive deflection peaking at $375 \mathrm{msec}$. The orientation attention effect possessed a similar time-course, although it was generally less prominent and consistent across the two gratings.

The results of the analysis of variance for the feature-specific attention effects are summarized in Table 1 . The main effect of spatial frequency first reached significance at $200 \mathrm{msec}[\mathrm{F}(1,7)=8.98, \mathrm{p}<$ $.05]$ and was most highly significant at $225 \mathrm{msec}$ $[F(1,7)=86.66, p<.001]$. It remained highly significant at $250 \mathrm{msec}[\mathrm{F}(1,7)=29.51, \mathrm{p}<.001]$ and $375 \mathrm{msec}[\mathrm{F}(1,7)=47.78, \mathrm{p}<.001]$. The main effect of orientation, on the other hand, did not attain initial significance until $225 \mathrm{msec}[F(1,7)=12.71$, $\mathrm{p}<.01$, although it likewise proved highly significant at both $250 \mathrm{msec}[\mathrm{F}(1,7)=27.77, \mathrm{p}<.001]$ and $375 \mathrm{msec}[\mathrm{F}(1,7)=32.38, \mathrm{p}<.001]$.

VEP grating-specific attention effects. The gratingspecific attention effect (shaded areas in Figures 4c and 5 ) is reflected by that portion of the increase in VEP amplitude from the "neither" to "spatial frequency \& orientation" attention conditions ( $\Delta \mathrm{SF}$ $\& O$, Figures $4 c$ and 5) which cannot be attributed to the summation of the feature-specific attention effects $(\Delta \mathrm{SF}+\Delta \mathrm{O}$, Figure $4 \mathrm{c})$. This effect has a later time-course than the feature-specific effects, starting at about $225 \mathrm{msec}$ and peaking at $375 \mathrm{msec}$ poststimulation. The feature-specific attention effects were proportionately greater at $225 \mathrm{msec}$, whereas the grating-specific attention effect was proportionately greater at $375 \mathrm{msec}$ (Figure 5).

With the exception of a significant value at $125 \mathrm{msec}[\mathrm{F}(1,7)=17.30, \mathrm{p}<.01]$, the spatial frequency $x$ orientation interaction effect, which assessed the magnitude of the grating-specific attention effect in the analysis of variance, revealed a similar trend (see Table 1). This interaction effect attained significance at $225 \mathrm{msec}[F(1,7)=6.06, p<$ 

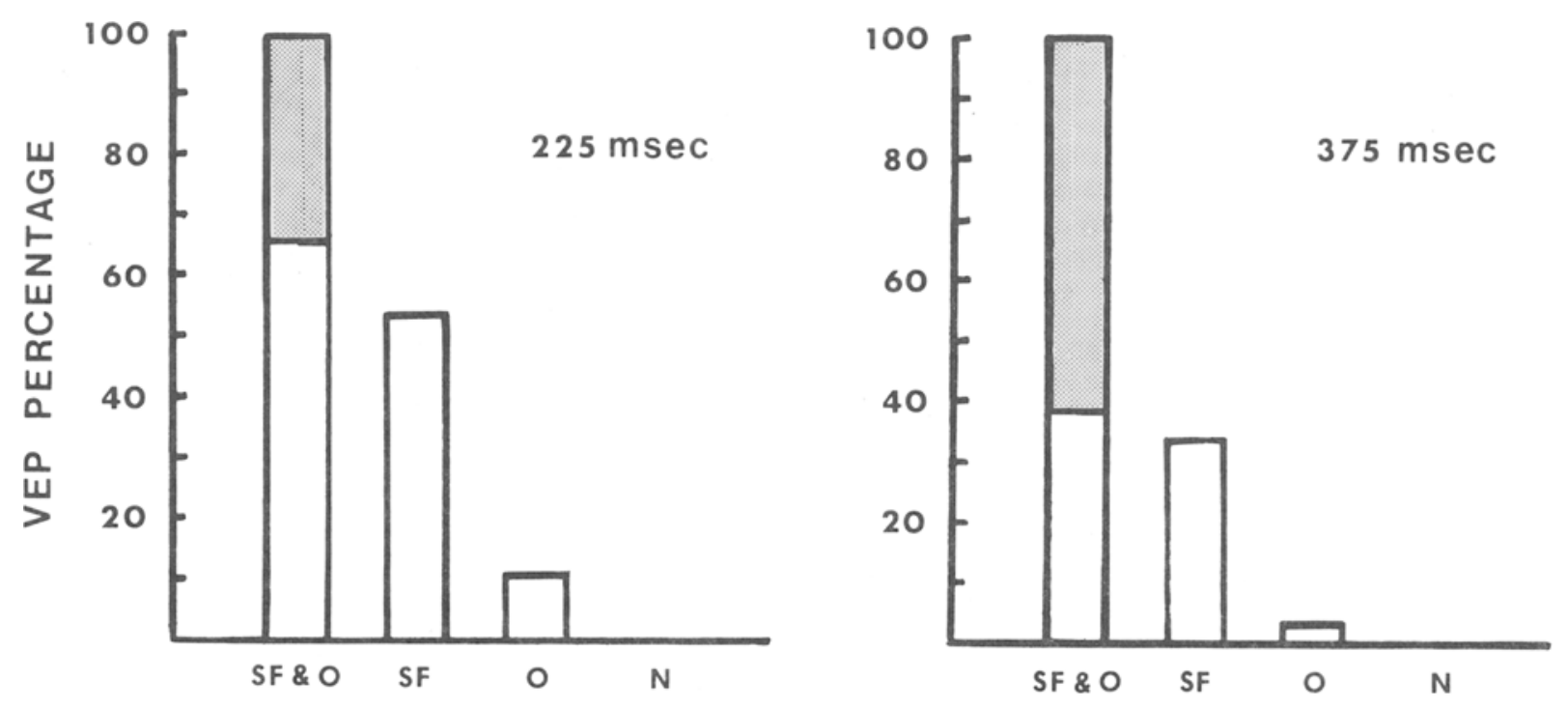

\section{ATTENTION CONDITION}

Figure 5. The percentage increase in VEP amplitude at $225 \mathrm{msec}$ (left) and $375 \mathrm{msec}$ (right) as a function of the four attention conditions, which varied in the number of features common to the fashed and relevant gratings. These are percentages of the total change in amplitude due to selectively attending the relevant grating-that is, the "neither" vs. "spatial frequency \& orientation" attention conditions. The shaded area in the "SF \&O" condition represents the increase in amplitude which cannot be attributed to the summation of the "SF" and " $O$ " feature-specific effects. The graphs are based upon data averaged across the two flashed gratings, eight subjects, and four replications.

$.05]$, at $250 \mathrm{msec}[\mathrm{F}(1,7)=10.21, \mathrm{p}<.05]$, and at $375 \mathrm{msec}[\mathrm{F}(1,7)=18.15, \mathrm{p}<.01]$.

Additional VEP effects. Several effects involving the flashed grating and replication factors also proved significant in the analysis of variance. They will be mentioned only briefly, since they were not relevant to the theoretical purposes of this study. The main effect of flashed grating proved significant at $75 \mathrm{msec}[\mathrm{F}(1,7)=16.60, \mathrm{p}<.01], 175 \mathrm{msec}[\mathrm{F}(1,7)=$ $10.73, \mathrm{p}<.05]$, and $200 \mathrm{msec}[\mathrm{F}(1,7)=15.93, \mathrm{p}<$ $.01]$. In addition, the flashed grating $x$ orientation interaction effect achieved significance at $125 \mathrm{msec}$ $[F(1,7)=19.16, p<.01]$; the flashed grating $\times$ spatial frequency $x$ orientation interaction effect attained significance at $375 \mathrm{msec}[F(1,7)=6.05$, $p<$ $.05]$; the replication $\times$ spatial frequency interaction effect proved significant at both $125 \mathrm{msec}[\mathrm{F}(3,21)=$ $6.16, \mathrm{p}<.01]$ and $175 \mathrm{msec}[\mathrm{F}(3,21)=3.42, \mathrm{p}<.05]$; the replication $x$ spatial frequency $x$ orientation interaction achieved significance at $175 \mathrm{msec}[F(3,21)$ $=3.42, \mathrm{p}<.05$; and finally, the replication $\times$ flashed grating $\times$ spatial frequency $\times$ orientation interaction effect proved significant at $125 \mathrm{msec}[\mathrm{F}(3,21)=4.42$, $\mathrm{p}<.05]$.

\section{Summary}

The most prominent overall aspect of the effect of attending to the gratings employed in the present study was a long negative voltage shift starting at about $175 \mathrm{msec}$ and peaking at $250 \mathrm{msec}$, followed by a positive shift peaking at $375 \mathrm{msec}$. Both feature-specific and grating-specific selection effects were evidenced in these fluctuations. With the exception of VEP activity at $125 \mathrm{msec}$, the feature-specific effects occurred slightly earlier in time than the grating-specific effects. The behavioral data primarily reflected grating-specific selection processes, and therefore most closely resembled VEP activity occurring after $225 \mathrm{msec}$.

\section{DISCUSSION}

The results of this study indicate that selective attention to gratings of a particular spatial frequency and orientation may be characterized by two general

Table 1

F Ratios for the Spatial Frequency, Orientation, and Spatial Frequency $\times$ Orientation Effects

\begin{tabular}{lcccccccc} 
& \multicolumn{8}{c}{ Latency (in Milliseconds) } \\
\cline { 2 - 7 } \multicolumn{1}{c}{ Effect } & 75 & 125 & 175 & 200 & 225 & 250 \\
\hline Spatial Frequency & 2.19 & .60 & 4.84 & $8.98^{*}$ & $86.66 \dagger$ & $29.59 \dagger$ & $47.78 \dagger$ \\
Orientation & 2.73 & .07 & 2.82 & .06 & $12.71^{* *}$ & $27.77^{\dagger}$ & $32.38 \dagger$ \\
Spatial Frequency & X Orientation & .39 & $17.30^{* *}$ & 2.29 & .58 & $6.07^{*}$ & $10.21^{*}$ & $18.15^{* *}$ \\
\hline
\end{tabular}

Note-For all $F$ ratios, $d f=1,7 . \quad{ }^{*} p<.05,{ }^{* *} p<.01, t_{p}<.001$. 
mechanisms: (1) one which is specific to the features contained in the relevant gratings, and (2) one which is specific to the conjunction of features which defines the relevant grating. In both the behavioral and VEP data, feature-specific selection processes were reflected in response activity that was "channelspecific," that is, occurred to irrelevant gratings that had either spatial frequency or orientation in common with the relevant grating. Grating-specific selection processes, on the other hand, were reflected in those effects which could not be predicted on the basis of feature-specific attention. These findings will be discussed both in terms of the role of featurespecific and grating-specific sensory mechanisms in mediating selective attention and in terms of the role of particular features and feature-conjunctions in other visual selection paradigms.

Before proceeding to a more detailed discussion of these two selection mechanisms, it should be noted that both feature-specific and grating-specific attentional processes were clearly evidenced in the extended negative voltage shift whose onset and peak occurred at approximately 175 and $250 \mathrm{msec}$, respectively. This finding lends further support to the view that this negative shift-termed N235 (Harter \& Salmon, 1972) or "processing negativity" - is actually a complex ensemble of individual components depicting various stages in the information-processing hierarchy (see Harter, Aine, \& Schroeder, 1982; Harter \& Guido, 1980; Harter \& Previc, 1978).

In the present study, the effects of orientationspecific and spatial frequency-specific attention upon the VEP may be characterized as a set of parallel negative voltage shifts with onset latencies of approximately $175 \mathrm{msec}$ and peak latencies of approximately 225-250 msec. The parallel nature of the feature-specific effects is consistent with the findings of information processing studies which have utilized choice RT and visual search paradigms (Saraga \& Shallice, 1973; Treisman, Sykes, \& Gelade, 1977), and the greater prominence of the spatial frequencyspecific attention effect is also consistent with findings concerning the relative salience of size and orientation cues in visual search (see Keren, 1976, for a review). The comparable time-course of the two feature-specific attention effects was not predicted on the basis of the Towle et al. (1980) study, however, which reported that orientation-specific suppression precedes spatial frequency-specific suppression by a substantial latency. On the basis of its time course, it would appear that orientation-specific attention is not mediated by the earliest orientationspecific suppression channels in the human visual system, although it may be mediated by orientationspecific suppression channels which are active later in time (see Towle et al., 1980). However, while the time course of the spatial frequency attention effect in the present study closely resembled that of the in- terocular spatial frequency suppression effect obtained by Towle et al. (1980), it may also be presumed not to have been mediated by the earliest spatial frequency-specific sensory channels reported in the VEP literature (see Smith \& Jeffreys, 1978). Thus, it may be tentatively concluded that in the case of both orientation and spatial frequency, featurespecific attention influences primarily those featurespecific sensory channels that are active later in time.

It may be presumed that the feature-specific attention effect occurred on the majority of irrelevant grating presentations regardless of whether a "false alarm" was actually made. If, however, this effect was present only when "false alarms" occurred, then it is possible that what has been termed a featurespecific attention effect may actually be a misplaced "grating-specific" effect, due to the fact that on "false-alarm" trials subjects mistakenly perceived the irrelevant grating as the target stimulus. Only an analysis of VEPs during "false-alarm" and "correctrejection" trials-which, in the present instance, was not possible-could provide definitive support for one of the above interpretations. However, there are at least two reasons for favoring the "feature attention" interpretation in this instance. First, a comparison of Figures 2 and 5 reveals that the relative prominence of feature attention effects in the VEP data clearly exceeded the relative percentage of feature-related RT responses. Second, the discrepant time courses of the feature-specific and gratingspecific attention effects render it highly unlikely that they manifested the same underlying process.

Grating-specific attention was reflected in two significant VEP effects in the present study. The most prominent of these occurred between 225 and $375 \mathrm{msec}$ poststimulation, and was evident in the latter portion of the extended negative voltage shift described earlier, as well as the subsequent positive deflection traditionally termed $P 300$. The fact that the onset of this grating-specific attention effect occurred subsequent to the onset of the featurespecific effects was predicted on the basis of the Towle et al. (1980) study, in which feature-specific sensory suppression effects also preceded gratingspecific ones. This finding would also have been predicted by models of pattern recognition and pattern selection which propose that such processes as pattern synthesis, selection on the basis of feature conjunctions, and target selection-all of which may be involved in grating-specific attention-are preceded by feature analysis and/or selection (see Rummelhart, 1977; Treisman, 1969; Treisman et al., 1977). Finally, this finding is consistent with a recent VEP study in which selective attention to word-color conjunctions was preceded by the selection of the word and color features (Aine \& Harter, 1981), as well as other VEP studies which have reported that dimensions of the target are selected prior to target selec- 
tion (Harter et al., 1982; Harter \& Guido, 1980; Harter \& Previc, 1978).

Although the vast majority of RT responses were directed towards the relevant grating, as required by the behavioral task, it is unlikely that the gratingspecific effect was purely a motor response potential. This is because similar potentials are evident even when subjects are not required to make an overt behavioral response to the relevant stimulus (Harter \& Previc, 1978; Harter \& Salmon, 1972). It is also unlikely that this effect was entirely a result of the fact that the relevant grating was presented on only onequarter of the trials. Although infrequent stimuli do elicit P300 components (Duncan-Johnson \& Donchin, 1977), these components can also be generated by a target stimulus when the probability of target and nontarget stimulus presentations is equated (Harter \& Salmon, 1972). Furthermore, a probability explanation by itself would have difficulty in accounting for the feature-specific attention effects which were present in VEPs to the more frequent irrelevant gratings. Finally, such an explanation would ignore the strong parallels between the results of this study and the concepts of feature-specific and featureconjunction selection processes previously described in the information processing literature.

A second, less pronounced grating-specific attention effect, which occurred prior to the earliest significant feature-specific attention effects, was distinguished by a remarkably short peak latency $(125 \mathrm{msec})$. This initial grating-specific effect was not predicted on the basis of the Towle et al. (1980) findings, and, presumably, it would not have been predicted by any of the above models. Nevertheless, it is consistent with pattern-recognition models which have postulated the existence of a "holistic" processing stage prior to feature analysis and selection (see Lockhead, 1972). It must be conceded, however, that the nature and reliability of this early gratingspecific attention effect require further delineation and replication before its potential significance may be adequately assessed.

Before concluding, a few brief speculations concerning the respective neural loci of feature and grating-specific attentional mechanisms may be made. On the basis of topographical findings reported by Harter et al. (1982) and Harter and Guido (1980), it is likely that the attention-related negative voltage shift between 175 and $250 \mathrm{msec}$ originated in extrastriate visual association cortical regions. While posterior extrastriate regions may be responsible for feature attention activity, inferotemporal cortex would appear to be a logical candidate for the locus of the subsequent grating-specific attention effects, given its higher order patternrecognition and target-selection capabilities (see Mishkin, 1972; Sahgal \& Iversen, 1978). Further evi- dence suggests that selective attention involving feature-conjunction activity may be lateralized in the left hemisphere (Aine \& Harter, 1981; Harter et al., 1982).

In summary, selective attention to gratings defined as a conjunction of spatial frequency and orientation features may be characterized in terms of two general processes-feature-specific and grating-specific selection. Feature-specific selection appears to be (1) parallel in nature, with spatial frequency more prominently reflected than orientation, and (2) mediated primarily by feature-specific sensory channels which occur later in time. Grating-specific selection begins subsequent to the onset of feature-specific selection, and may be associated with a distinct neural locus.

\section{REFERENCES}

Aine, C. J., \& Harten, M. R. Event-related potentials to Stroop stimuli: Color and word processing. Precirculated Abstracts of the Sixth International Conference on Event-Related Slow Potentials of the Brain, 1981, 6, 1-2.

Braddick, O., Campeell, F. W., \& Atkingon, J. Channels in vision: Basic aspects. In R. Held, H. W. Leibowitz, \& H. L. Teuber (Eds.), Handbook of sensory physiology (Vol. 7). Berlin: Springer-Verlag, 1978.

Duncan-Johnson, C. C., \& Donchin, E. On quantifying surprise: The variation in event-related potentials with subjective probability. Psychophysiology, 1977, 14, 456-467.

Eason, R. G., Harter, M. R., \& White, C. T. Effects of attention and arousal on visual evoked cortical potentials and reaction time in man. Physiology \& Behavior, 1969, 4, 283-289.

Harter, M. R., Aine, C., \& Schroeder, C. Hemispheric differences in the neural processing of stimulus locations and type: Effects of selective attention on visual evoked potentials. Neuropsychologia, 1982, 20, 421-438.

Harter, M. R., Conder, E. S., \& Towle, V. L. Orientationspecific and luminance effects: Interocular suppression of visual evoked potentials. Psychophysiology, 1980, 17, 141-145.

Harter, M, R., \& Guido, W. Attention to pattern orientation: Negative cortical potentials, reaction time, and the selection process. Electroencephalography and Clinical Neurophysiology, $1980,49,461-475$.

Harter, M. R., \& Previc, F. H. Size-specific information channels and selective attention: Visual evoked potential and behavioral measures. Electroencephalography and Clinical Neurophysiology, 1978, 45, 628-640.

HARTER, M. R., \& SALmon, L. E. Intra-modality selective attention and evoked cortical potentials to randomly presented patterns. Electroencephalography and Clinical Neurophysiology, $1972,32,605-613$

Harter, M. R., Towle, V. L., \& Musso, M. Size specificity and interocular suppression: Monocular evoked potentials and reaction times. Vision Research, 1976, 16, 1111-1117.

KE PPEL, G. Design and analysis: $A$ researcher's handbook. Englewood Cliffs, N.J: Prentice-Hall, 1973.

KEREN, G. Some considerations on two kinds of selective attention. Journal of Experimental Psychology: General, 1976, 105, 349-374.

Lockhead, G. R. Processing dimensional stimuli: A note. Psychological Review, 1972, 79, 410-419.

Mishin, M. Cortical visual areas and their interaction. In A. G. Karczmar \& J. C. Eccles (Eds.), The brain and human behavior. Berlin: Springer-Verlag, 1972. 
RUMmelhart, D. E. Introduction to human information processing. New York: Wiley, 1977.

Sahgal, A., \& Iverson, S. D. Categorization and retrieval after selective inferotemporal lesions in monkeys. Brain Research, $1978,146,431-450$.

Saraga, E., \& Shallice, T. Parallel processing of the attributes of single stimuli. Perception \& Psychophysics, 1973, 13, 261-270.

SMITh, A. T., \& JefFreYs, D. A. Size and orientation specificity of transient visual evoked potentials in man. Vision Research, 1978, 18, 651-655.

Towle, V. L., Harter, M. R., \& Previc, F. H. Binocular interaction of orientation and spatial frequency channels: Evoked potentials and observer sensitivity. Perception \& Psychophysics, $1980,27,351-360$.

Treisman, A. M. Strategies and models of selective attention. Psychological Review, 1969, 76, 282-299.

Treisman, A. M., Sykes, M., \& Gelade, G. Selective attention and stimulus integration. In S. Dornic (Ed.), Attention and performance VI. New York: Wiley, 1977.
Van VoORhis, S., \& Hillyand, S. A. Visual evoked potentials and selective attention to points in space. Perception \& Psychophysics, 1977, 22, 54-62.

\section{NOTE}

1. At the Sixth International Conference on Event-Related Slow Potentials of the Brain, Lake Forest, Illinois, 1981, the panel on negative potentials and information processing (Walter Ritter, Judith Ford, Anthony Gaillard, Russell Harter, Marta Kutas, Risto Näätänen, John Polich, Bernard Renault, and John Rohrbaugh) agreed that the negative potentials reported by Harter and his colleagues were members of the family of components termed "processing negativity" by Näätänen and his colleagues.

(Manuscript received February 8, 1982; revision accepted for publication August 16, 1982.) 